\title{
From Labyrinth to Piano Key Weirs - A historical review
}

\author{
A.J. Schleiss \\ Professor, Director of Laboratory of Hydraulic Constructions (LCH), Ecole Polytechnique Fédérale de \\ Lausanne (EPFL), Switzerland
}

\begin{abstract}
Free crest spillways are hydraulically efficient and safe in operation. Since their discharge capacity is directly proportional to the crest length several types have been developed with the purpose to increase the length of the latter. Among these types traditional labyrinth weir spillways have been studied and used for a long time. Their hydraulic performance and the effect of the involved geometrical parameters are well known. Nevertheless, their design still has to be based on experimentally derived and generalized performance curves.

The recently introduced Piano Key weirs present clear advantages regarding hydraulic performance and construction costs compared to classical labyrinth weirs. Especially its small footprint makes the PK weir an efficient and cost effective solution for the increase of the flood releasing capacity at existing concrete gravity dams. Until today only preliminary design procedures are available which cannot yet be generalized. The still ongoing research on this complex hydraulic structure is a challenge for many scientists all over the world. Despite of this, several prototypes have been installed successfully over the last years on existing dams which enhance efficiently the flood release capacity.
\end{abstract}

\section{INTRODUCTION}

Spillways play a major role in ensuring the flood safety of dams. Insufficient spillway capacity has been the cause of one-third of all dam failures.

The discharge capacity of free crest or ungated overfall spillways is directly proportional to the length of the ogee crest or the weir for a given upstream head. Its length can be increased by using curved, ondulated or corrugated weirs instead of straight linear weirs. Consequently the discharge for a given head also increases. Nevertheless, the channel or chute downstream of the weir should also have a sufficient evacuation capacity.

With the motivation of maximizing the crest length, the following crest geometries of weirs have so far been developed (Figure 1):

a) Duckbill spillway or bathtube spillway (in case of parallel side walls)

b) Fan spillway

c) Type Y spillway

d) Daisy-shape (marguerite), morning glory spillway

In a further step, the labyrinth spillways (Figure 2) were developed starting in the thirties of the last century. After 2000, the Piano Key weir (PK weir) was introduced as an evolution of the traditional labyrinth weirs. The paper presents a short historical review on the development and design of labyrinth and PK weirs. 


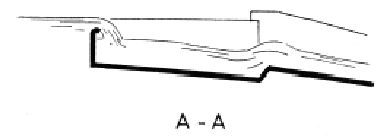

a)
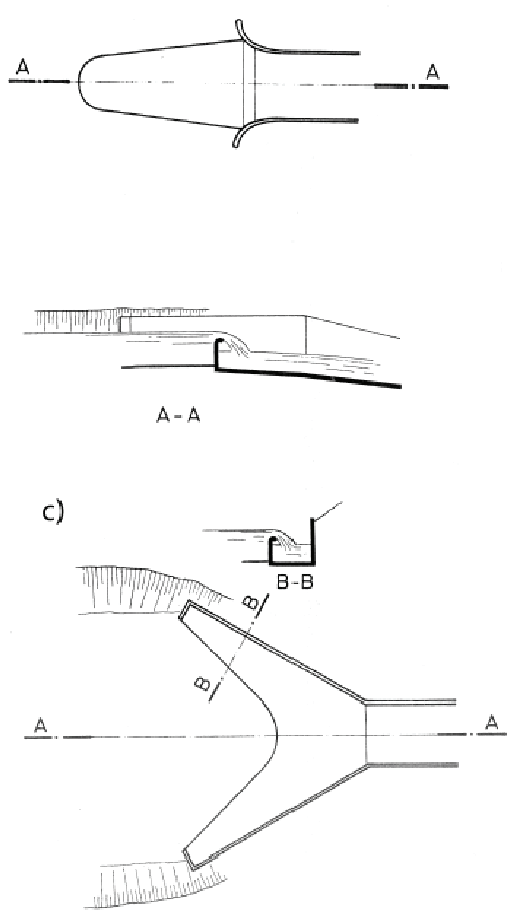

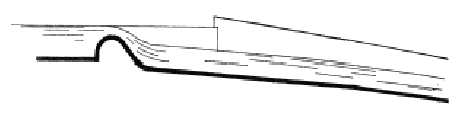

$A-A$
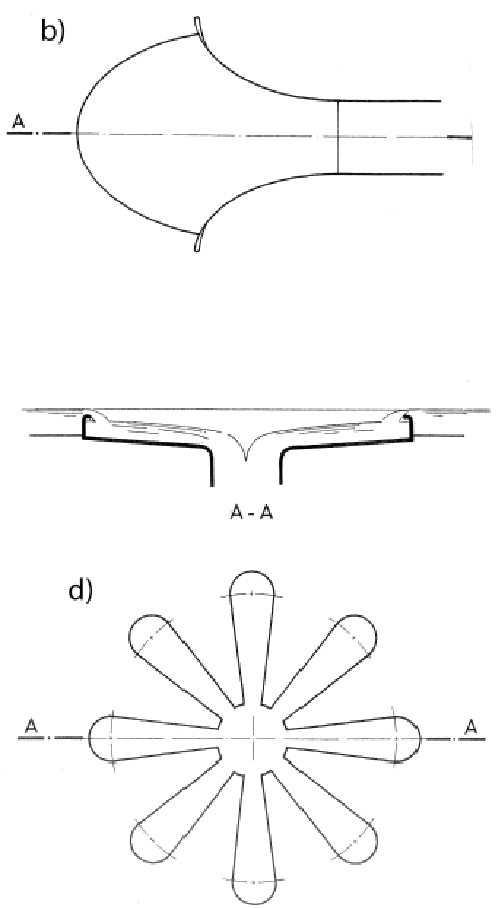

Figure 1 Curved or undulated weirs (ICOLD, 1994):

a) Duckbill spillways, b) Fan spillways

c) Type Y spillways,

d) Daisy-shape (marguerite), morning glory spillway
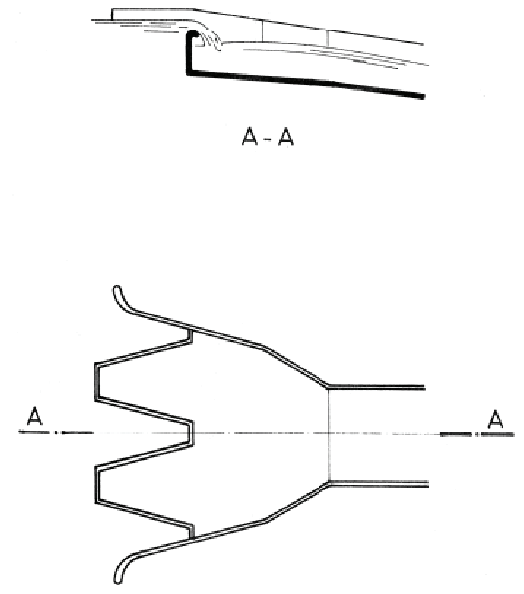

Figure 2 Layout and longitudinal section of a labyrinth weir (ICOLD, 1994). 


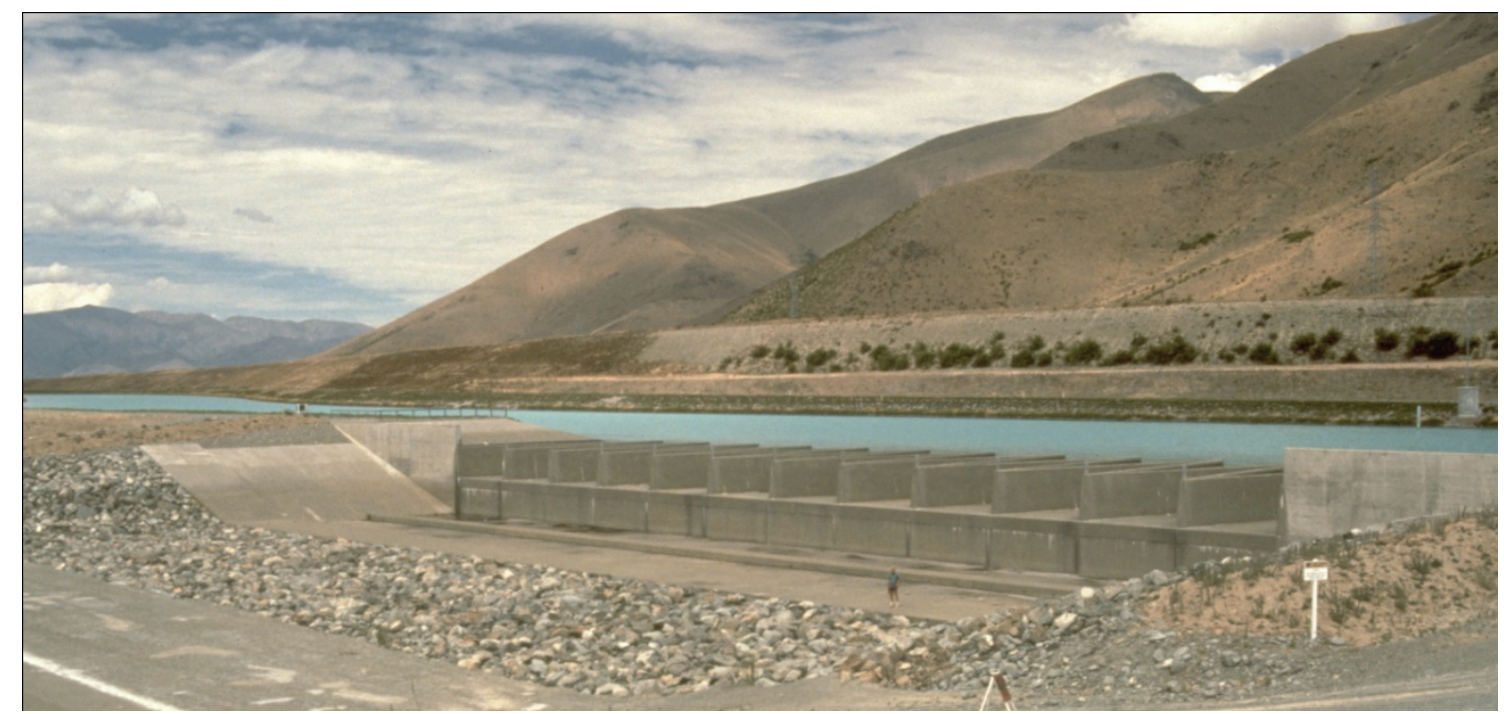

Figure 3 Labyrinth weir at Ohau river in New Zealand at the connecting canal between Ohau B and Ohau C hydroelectric power plant.

\section{LABYRINTH WEIRS}

\subsection{Use and types of labyrinth weirs}

Labyrinth weirs can pass large flows at comparatively low heads. They are primarily used as spillways for dams where the spillway width is restricted or where the flood surcharge space is limited (Lux \& Hinchliff, 1985). Since labyrinth weirs are relatively low cost spillways compared to gated spillways, they are often used in conjunction with raising of dams for increased storage volume. Another reason for their use is often the upgrading of the flood discharge capacity at existing dams, especially at concrete gravity dams. Labyrinth weirs are also used as protection structures for canals and run-of-river hydroelectric plants (Figure 3).

Furthermore, Falvey (2003) cites the use of labyrinth weirs as energy dissipaters, applied to control water quality by aering or de-aerating the flow. An overview of the characteristics of existing labyrinth installations is given by Lux \& Hinchliff (1985) and Pinto Magalhães (1985).

The distinguishing characteristic of labyrinth spillways is that the plan shape is not linear but varies using a repeating planform as

- U shape (eventually rectangular),

- V or triangular shape (Figure 4) and

- trapezoidal shape (Figure 5).

Depending on the application, the crest of the weir may have different shapes as (Falvey, 2003)

- sharp or narrow crest,

- flat crest,

- quarter-round crest,

- half-round crest and

- ogee crest.

The labyrinth planform can follow a straight axis (normal case) or a curved axis as shown in Figure 6. 


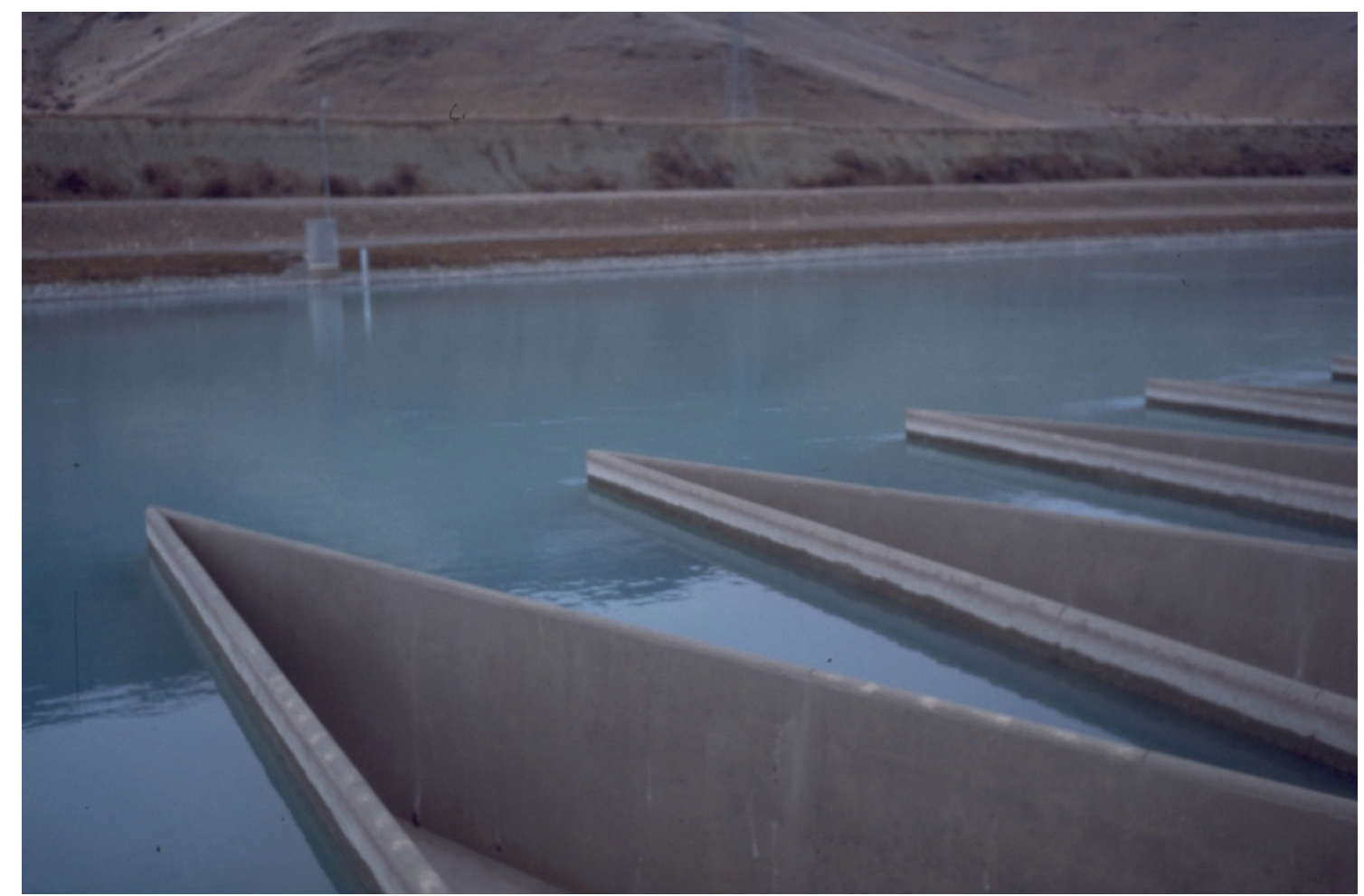

Figure 4 Triangular labyrinth weir of the hydroelectric power plant Ohau C in New Zealand.

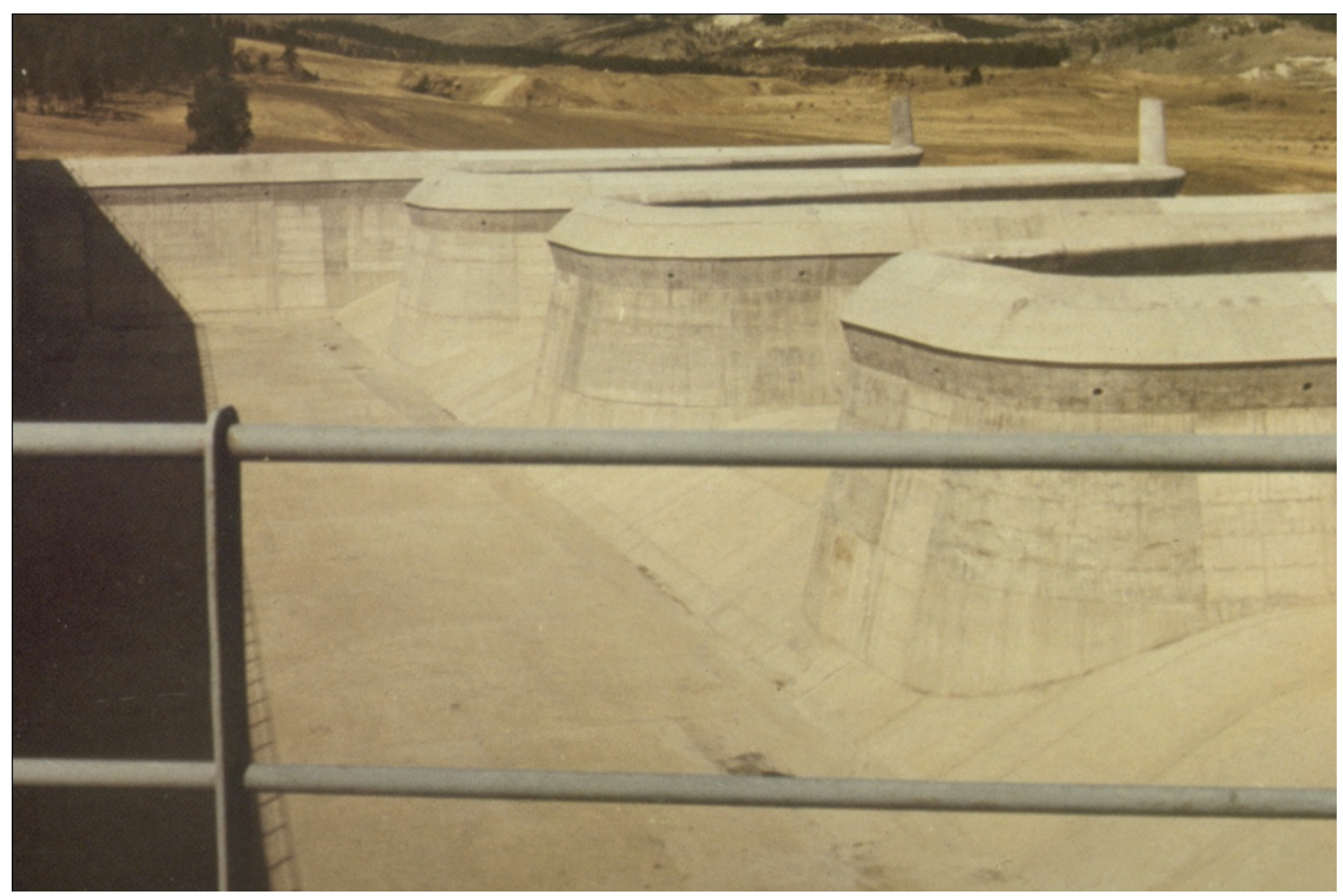

Figure 5 Trapezoidal labyrinth weir of Cimia dam in Italy. 


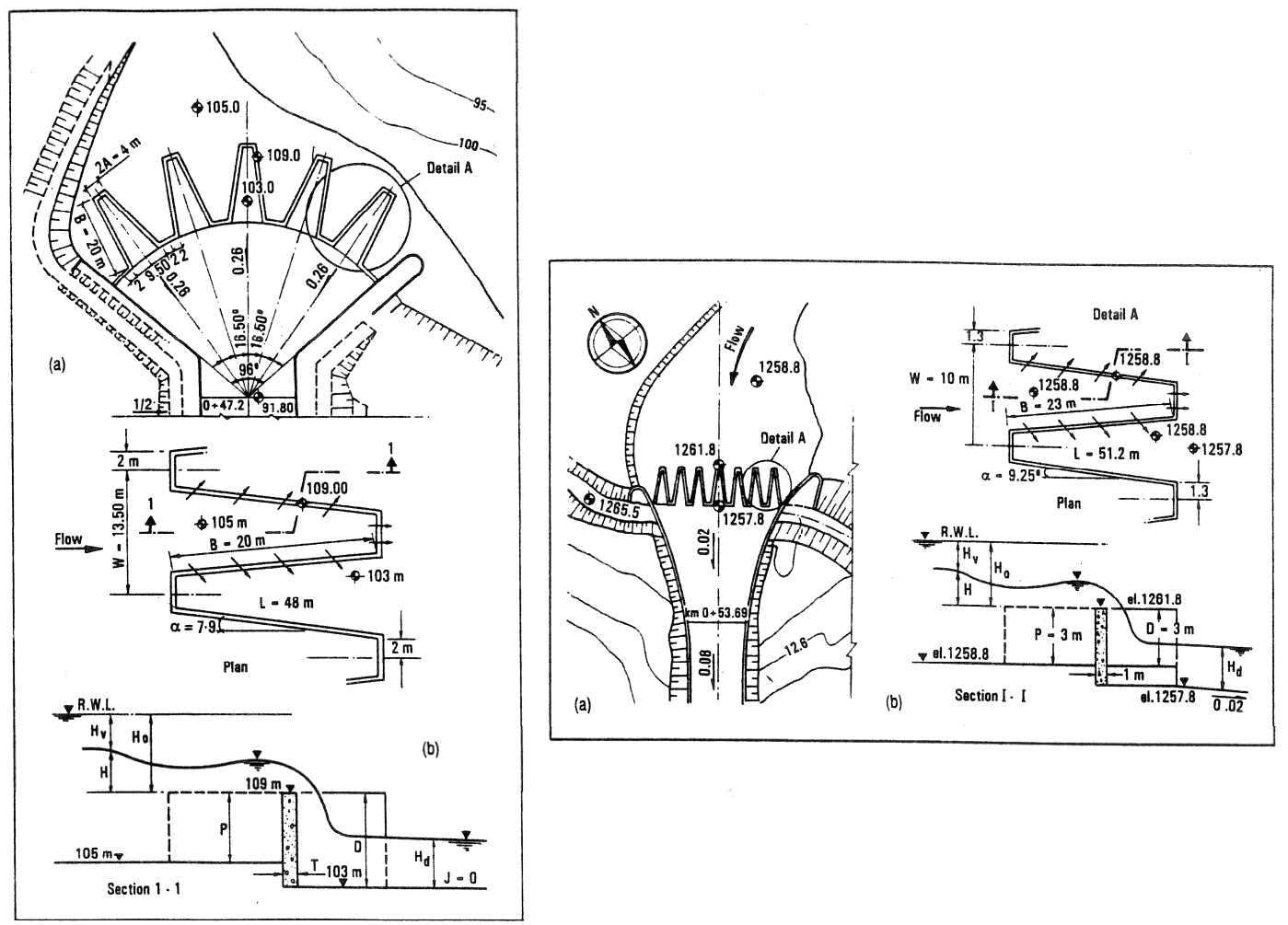

Figure 6 Curved and straight planform axis of Kizilcapinar (left) and Sarioglan (right) labyrinth spillway in Turkey (from Yildiz \& Üzücek, 1996)

\subsection{Labyrinth flow description}

As mentioned in the introduction, the discharge passing over a labyrinth weir should increase directly proportional with crest length. However, this is only the case for labyrinth spillways operating under low heads. Qualitatively, as the upstream head increases, the flow pattern sequently passes through four basic phases namely fully aerated, partially aerated, transitional and suppressed (Lux \& Hinchliff, 1985).

In the fully aerated phase, the flow falls freely over the entire length of the labyrinth crest. For this flow phase the thickness of the nappe and depth of tailwater has no influence on the discharge capacity of the labyrinth spillway, which has the same behavior as linear weir with the same vertical cross section.

As head increases, the flow becomes partially aerated due to convergence of opposing nappes and higher tailwater depths. The aeration becomes difficult because of the onset of nappe interference and results in a lowering of the discharge coefficient. A stable air pocket is formed along each side wall and downstream apex of the labyrinth.

By further increasing of upstream head and tailwater depth, the nappe becomes suppressed at various locations. The stable air pocket breaks up into smaller pockets that intermittently move upstream along the side walls causing instability in the nappe. This condition is the beginning of the transitional phase, which is difficult to observe precisely in the laboratory. Nevertheless, the transitional region can be easily identified as a slope change in the discharge coefficient curve (Figure 9).

Finally, if the flow forms a solid and non-aerated nappe, it is in the suppressed phase and no air is drawn under the nappe. Complete submergence will occur if the head above the crest is greater than the height of labyrinth weir. Its efficiency decreases rapidly approaching that of a linear crest with a length equal to the canal or chute width but with a rather low discharge coefficient. This phase should obviously be avoided for the design flood of the spillway, since the upstream head would increase more rapidly with increasing discharge. 


\subsection{Determination of labyrinth discharge capacity}

Flow over labyrinth weirs is very complex as it is three-dimensional and influenced by many parameters. Therefore, a large number of laboratory tests are needed to determine empirically the influence of the various parameters on the discharge capacity.

The first reported study of labyrinth weirs was conducted by Gentilini (1941) in Italy. In a laboratory flume several configurations of corrugated, triangular sharp crested weirs were tested and compared with linear oblique or perpendicular weirs (Figure 7). He compared the ratio of the Bazin/Rehbock discharge coefficient for linear weirs and those configurations with the ratio head over weir height (Figure 8).
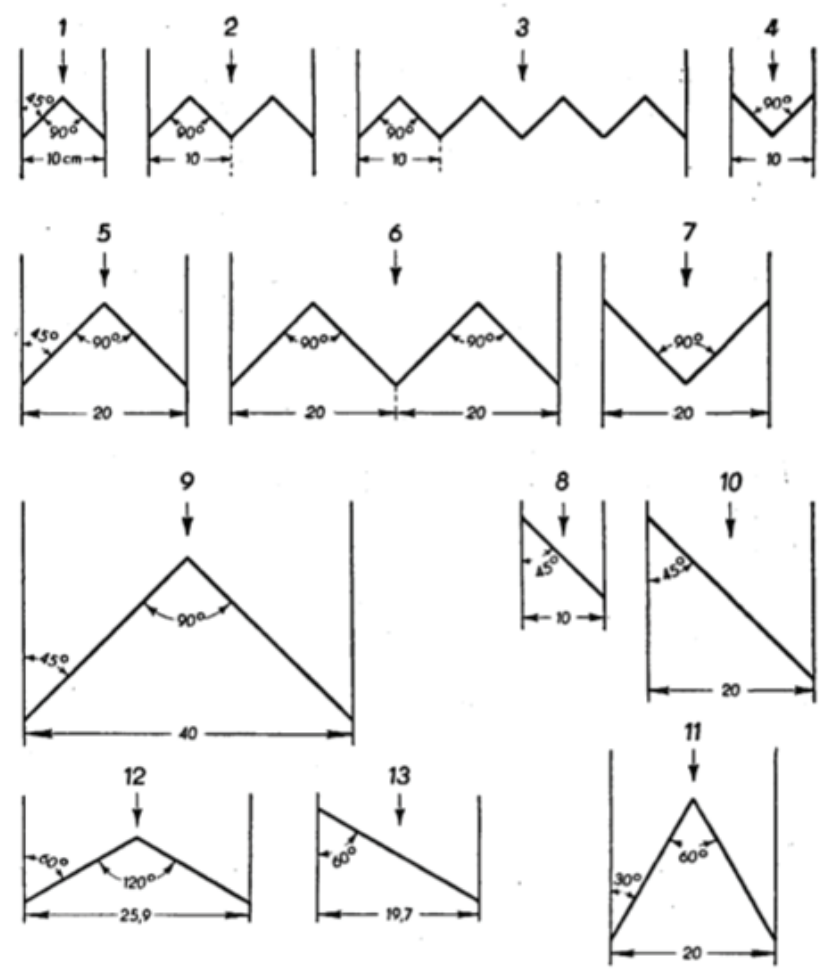

Figure 7 Oblique and corrugated triangular weir configurations tested by Gentilini (1941)

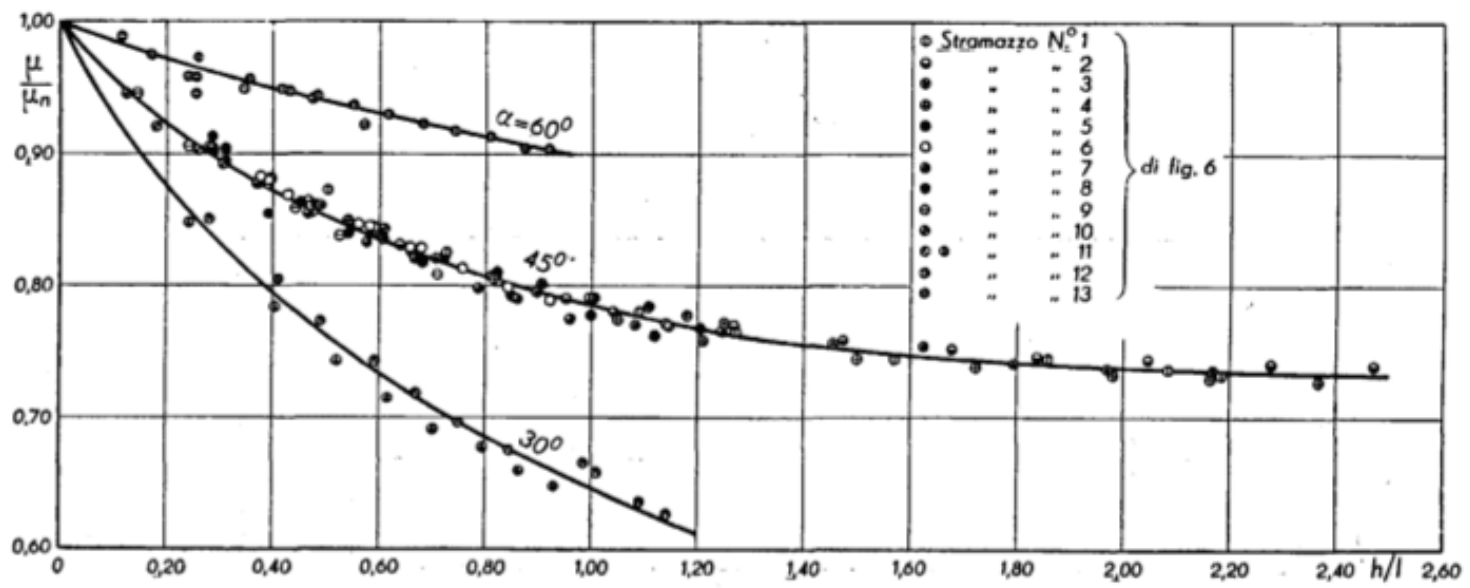

Figure 8 Discharge coefficient ratio $\mu / \mu_{n}$ as a function of total head $h$ over weir height $l$ ( $\mu=q / \sqrt{2 g} h^{3 / 2} ; \mu_{\mathrm{n}}$ for linear weirs according Bazin/Rehbock) (Gentilini, 1941). Tested configurations No 1 to 13 according Figure 7. Original notations have been conserved. 
It lasted almost 30 years before the first study was started by Taylor (1968) with the purpose to produce design-oriented labyrinth weir data (Hay and Taylor, 1970).

Darvas (1971) utilized the results from hydraulic models studies (Avon and Woronora Dam) to expand the theory and developed a family of curves to evaluate spillway performance.

Then the USBR performed also some labyrinth flume studies because the spillway design dimensions of Ute Dam exceeded the range of application of Taylor's study (Houston, 1982). It has to be mentioned that Taylor's analysis used piezometric head over the weir $h$ rather than the total head $H_{t}$ (or $\left.H_{o}\right)$ as the USBR tests. If comparing test results from different sources, the data has to be converted since the velocity head in the flume cannot be neglected $\left(H_{t}=h+V^{2} / 2 g\right)$. An overview of the tests performed by USBR is given in Lux \& Hinchliff (1985). The derived discharge coefficients were defined according to

$$
Q=C_{w}\left(\frac{\frac{W}{P}}{\frac{W}{P}+k}\right) W H_{0} \sqrt{g H_{0}}
$$

where $Q$ is the discharge per cycle, $W$ is the cycle width, $P$ is the upstream wall height and $H_{o}$ is the total upstream head. The fitted parameter $k$ is a constant having values of 0.18 and 0.10 for triangular and trapezoidal $(A / W=0.0765)$ planforms respectively. The crest length $L$ per cycle width $W$ becomes

$$
L=4 A+2 B
$$

with apex half length $A$ and wall length $B$. Design curves for quarter-round crests labyrinth weirs were developed (Figure 9). The discharge coefficient $C_{w}$ uses the subscript w since it is based on the vertical aspect ratio correlations. The total discharge of the labyrinth weir $Q_{t}$ can be calculated by multiplying $Q$ by the number of cycles $n$. Alternatively the total spillway width $W_{t}$ instead of the cycle width $W$ can be used in Eq. (1).
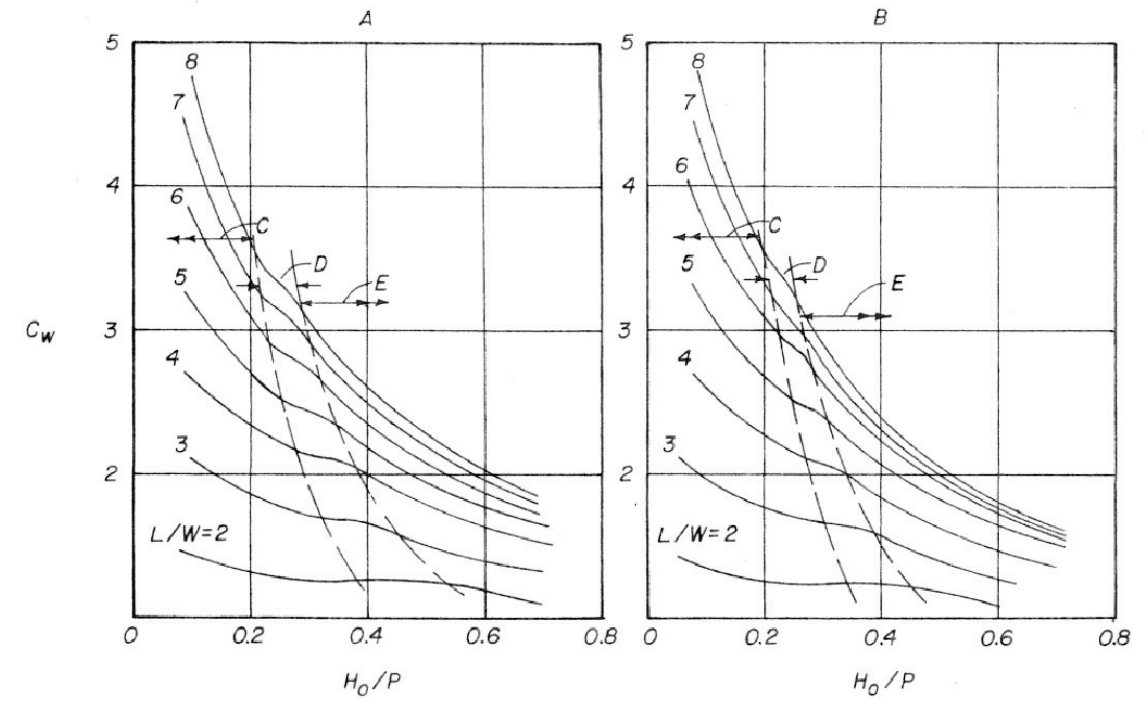

Figure 9 Design curves for quarter-round-crested labyrinth weirs:

(A) Triangular labyrinth weir (left); (B) Trapezoidal labyrinth weir (right); (C) Aerated nappe region, (D) Transitional and (E) Suppressed nappe region (from Lux \& Hinchliff, 1985).

Pinto Magalhães (1985) modified Darvas (1971) design chart by using a dimensionless discharge coefficient and new experimental results. The latter confirmed that the measured dis- 
charges were systematically lower that those indicated by Darvas (1971), in particular for high values of $H_{o} / P$.

Based on extensive experimental work at Utah Water Research Laboratory (UWRL), Tullis et al. (1995) developed a simplified design method using the standard weir equation:

$$
Q=\frac{2}{3} C_{d} L_{c} \sqrt{2 g} H_{T}{ }^{3 / 2}
$$

where $Q$ is the discharge of a labyrinth weir, $C_{d}$ is a dimensional discharge coefficient and $H_{T}$ the total upstream head. They replaced the total weir length in Eq. (3) with an effective weir length $L_{e}$. This is a more physical based approach to take into account for apex influences on discharge efficiency than the "black box mixing" of all influences in the discharge coefficient. In his detailed compilation and discussion of the published information on labyrinth weirs, Falvey (2003) favored also this design method. Tullis et al. (2005) conducted further tests to optimize the performance of low head $7^{\circ}$ and $8^{\circ}$ labyrinth weirs.

The effect of tailwater submergence on a dimensionless submerged head discharge relationship was studied by Tullis et al. (2007). Lopez et al. (2008) evaluated characteristics tailwater depth and energy dissipation downstream of a labyrinth weir. More recently Khode et al. (2010) performed experiments on wall angles of $21^{\circ}, 26^{\circ}$ and $30^{\circ}$ in order to validate the linear interpolation of the $\mathrm{C}_{\mathrm{d}}$ curves for $25^{\circ}$ and $35^{\circ}$ by Tullis et al. (1995).

Crookston (2010) recently tested 32 new hydraulic labyrinth weir models at UWRL. The discharge coefficient data obtained for quarter-round labyrinth weirs with side wall angles $6^{\circ} \leq \alpha \leq 35^{\circ}$ are compared with those of Tullis et al. (1995) and Willmore (2004). The improved $C_{d}$ data is recommended for use in determining labyrinth weir discharge relationships (Crookston \& Tullis, 2011) (see these Proceedings). Finally, the cycle efficiency is introduced as new parameter which allows a more rapid evaluation of relative discharge efficiencies of various labyrinth weir geometries. It has to be noted that the discharge coefficient was calculated as function of the weir centerline length and not of the effective length as used in Tullis et al. (1995).

\subsection{Hydraulic and structural design consideration}

Due to its geometry and large discharge capacity, a labyrinth spillway is particularly sensitive to reservoir approach flow conditions (Lux \& Hinchliff, 1985). The direction of the approach flow should be perpendicular to the alignment axis for the labyrinth.

The design of the upstream apexes aims an optimum compromise between using a larger trapezoidal apex for ease of construction as well as to minimize nappe interference and an almost triangular planform to limit entrance loss. The approach condition of the end cycle towards the lateral canal wall is also very important. Most efficient is the use of a vertical wall laid out on a radius adjacent to each end cycle of the labyrinth (Houston, 1982) (see Figure 6 right). If the labyrinth weir is placed as far upstream into the reservoir as possible, the entrance losses are reduced since the flow does not have to be channelized before passing over the labyrinth.

The flow out of the labyrinth in the chute downstream should be supercritical. If this is not possible the labyrinth should be designed such that maximum head to crest ratio $H_{o} / P$ remains in the aerated region.

The number of labyrinth cycles is directly related to the nappe interference. Therefore, for normal operating conditions, the vertical aspect ratio $W / P$, should be higher than 2.0 and 2.5 for trapezoidal and triangular shapes respectively (Hay \& Taylor, 1970).

At low flow conditions a non-aerated clinging nappe can occur, which produces nappe oscillation and noise. This should be avoided to prevent structural problems caused by vibrations and resonance. A common solution against a clinging nappe is the installation of splitter piers. Air may also be supplied through vents in labyrinth walls if thick enough.

Further recommendations on structural analysis and construction can be found in Lux \& Hinchliff (1995). 


\section{PK WEIRS}

\subsection{Use and types of $P K$ weirs}

The recent developed Piano Key weir (PK weir) spillway is a variation of traditional labyrinth weirs. The planform has a rectangular shape (Figure 10). Contrary to a labyrinth weir the apex is not vertical but inclined by turns both, in upstream and in downstream direction. This arrangement explains the name Piano Key weir. According to the chosen slopes of the inlet and outlet keys they have a certain upstream and downstream overhang. This result in a smaller footprint of the structure compared to a rectangular labyrinth weir with vertical walls. Therefore, besides an improved hydraulic performance, the PK weir has the advantage that it may be easily installed even at very limited foundation space as for example on gravity dam crests. This is also the reason why PK weir spillways are a efficient and economical solution for the increase of the flood releasing capacity at existing gravity dams. The first PK weir was installed in 2006 at Golours dam in France (Laugier, 2007). Since then PK weirs have been used to increase the flood discharge capacity of the three other EDF dams, namely St. Marc (2008), Etroit (2009) and Gloriettes (2010). PK weir spillways can be easily combined with stepped chutes which lead to a pronounced downstream energy dissipation (Bieri et al., 2009). Lessons learnt from the design of these four PK weir spillways can be found in Laugier et al. (2009) and Vermenten et al. (2011) (in these Proceedings).

Other PK weir developments are presently conducted in Vietnam (Chi Hien et al., 2006), India (Sharma \& Singhal, 2008) and France (Gage, Malarce and La Raviège Dam).

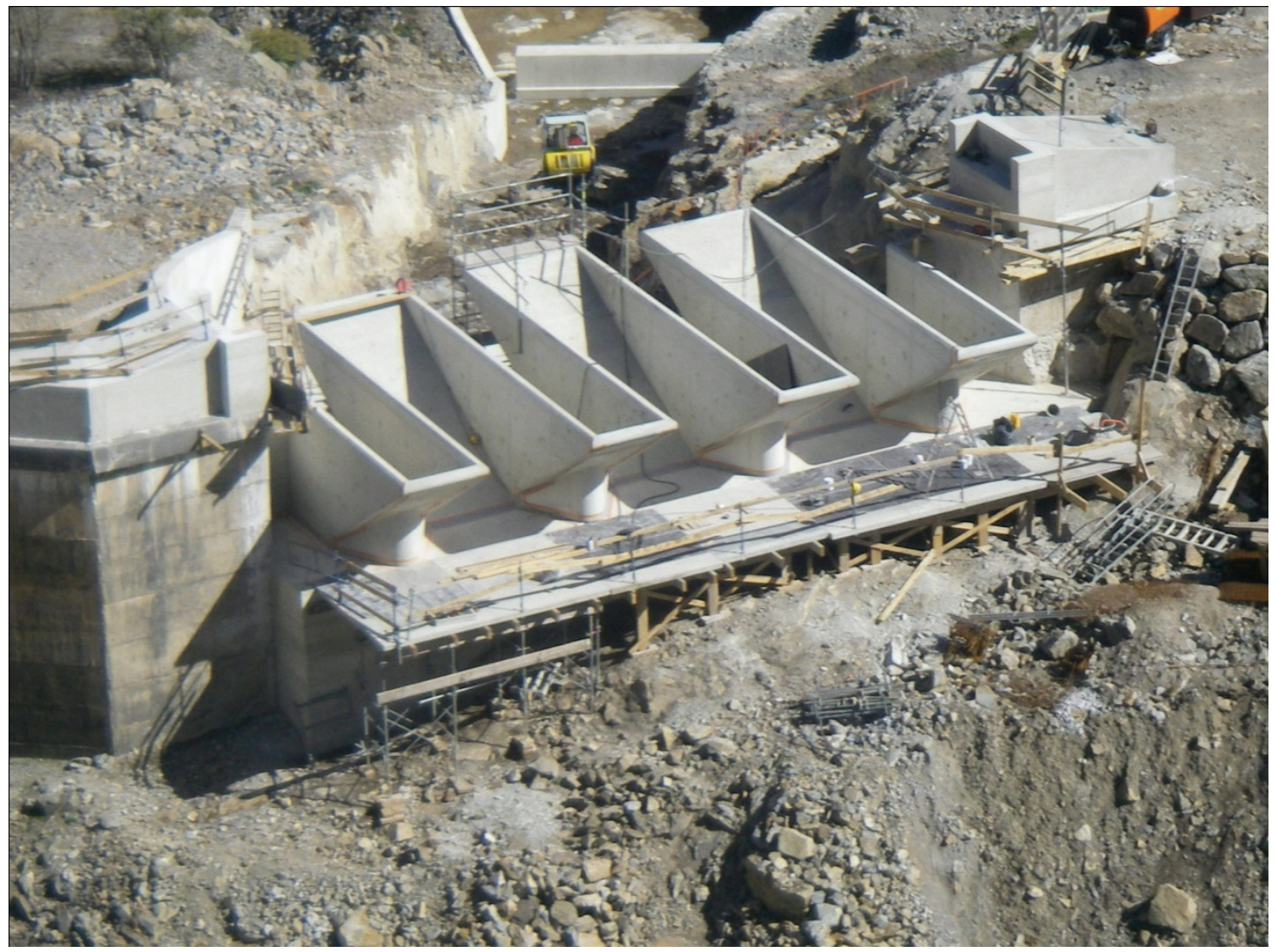

Figure 10 View of a PK weir spillway of Gloriettes dam in France during construction (Photo : EDF)

Initially, two main types of PK weir have been identified (Lempérière \& Ouamane, 2003):

Configuration A: The chutes (apex) are overhanging on both the upstream and downstream sides (Figure 11). This self-balanced structure favors the use of precast concrete elements and may be used for specific discharges up to $20 \mathrm{~m}^{3} /(\mathrm{sm})$. The relatively small footprint of the foundation allows placing this configuration on existing gravity dam crests in order to increase the flood release capacity as already mentioned. 
Configuration B: The chutes (apex) have only an upstream overhang (Figure 12). Structural loads are less for high specific discharges which makes this configuration attractive for new dam projects. Specific discharges up to $100 \mathrm{~m}^{3} /(\mathrm{sm})$ can be allowed.
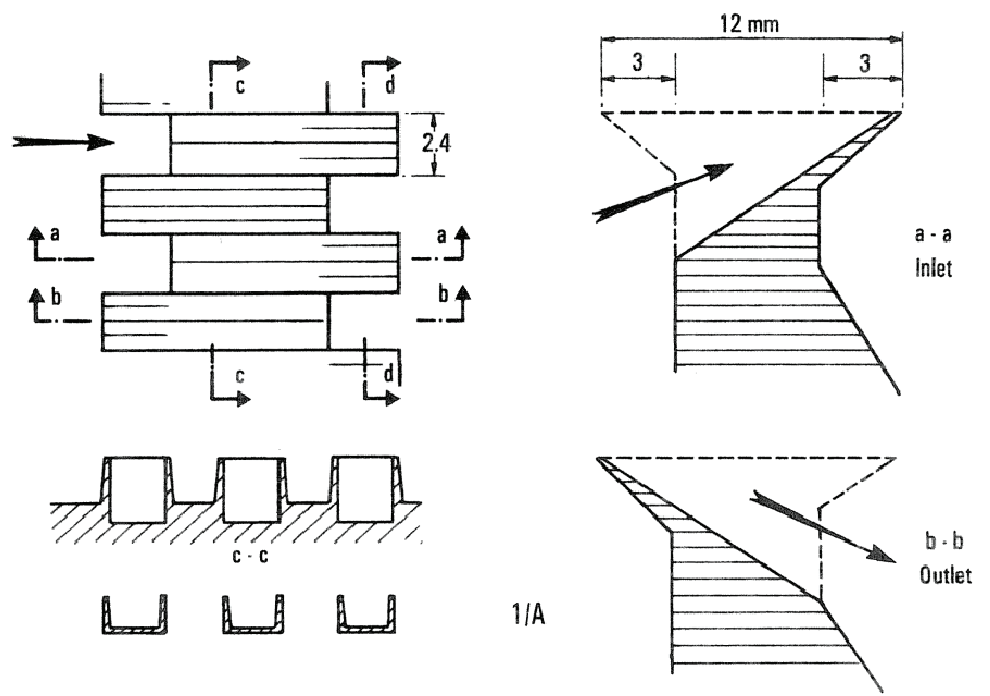

Figure 11 Configuration A of a PK weir (from Lempérière \& Ouamane, 2003)
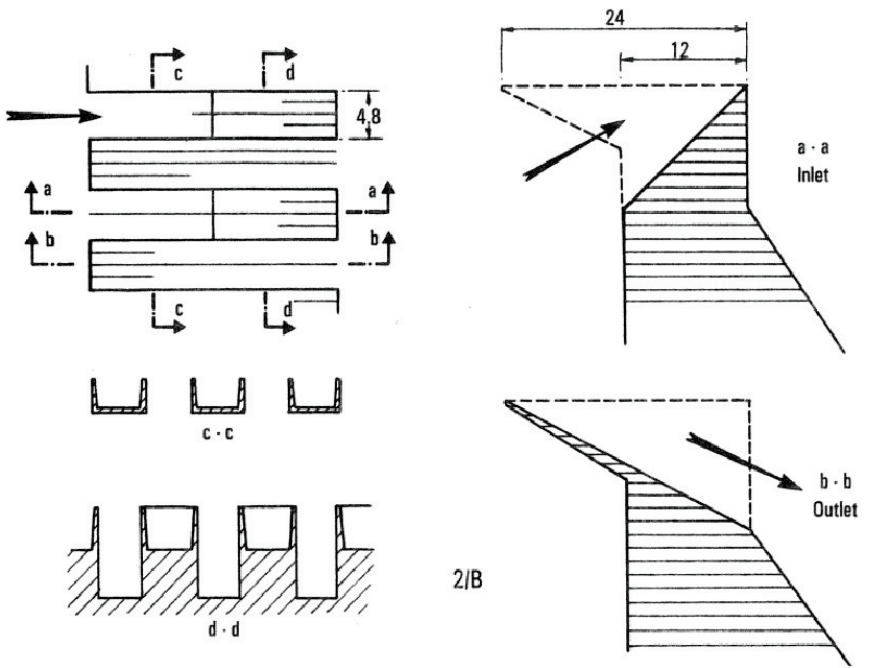

Figure 12 Configuration B of a PK weir (from Lempérière \& Ouamane, 2003)

Many optional features have been developed compared to the basic configurations as :

a) Parapet Walls: Vertical parapet walls placed on the crest of the PK weir transform its upper part to a rectangular labyrinth weir. The parapet wall on the outlet key increases the discharge capacity since it improves the stream line pattern of the approaching flow and increases the outlet key volume (Vermeulen et al., 2011).

b) Width of inlet and outlet keys: choosing a higher width of the inlet key than that of the outlet key results in a better hydraulic performance (Le Doucen et al., 2009).

c) Sidewall angle: a sidewall angle narrowing the inlet key and widening the outlet key are likely to improve the discharge capacity. 


\subsection{PK weir flow description}

Similar flow features may be observed as for traditional labyrinth weirs. Nevertheless, the influence of the downstream water level is of low relevance.

For low heads the transition from a partially clinging nappe to a leaping and then to a springing nappe can be observed on the different parts of the PK weir crest (Machiels et al., 2009b). For high heads the downstream crest of the inlet key is more supplied than the lateral crest. On the other hand the upstream crest of the outlet key is similarly supplied for high and low upstream head. For increasing heads a critical section appears from the downstream along the inlet key.

\subsection{Determination of $P K$ weir discharge capacity}

In the case of a PK weir even more parameters influence the three-dimensional flow than compared to a labyrinth weir. Therefore, a large number of systematic laboratory experiments on physical models of PK weirs are required in order to establish general applicable design rules.

Preliminary design criteria were presented by Lempérière \& Ouamane (2003) and Ouamane \& Lempérière (2006) which were based on experiments performed at Biskra University in Algeria and at Roorkee University in India (Lempérière et al., 2003). Since then more systematic laboratory experiments have been performed at EDF National Hydraulic Laboratory (EDF-LNHE Chatou) in France (Cicéro et al., 2010), at HACH-Hydraulic Laboratory of University of Liège, Belgium (Machiels et al., 2009a) and at the Laboratory of Hydraulic Constructions (LCHEPFL) in Lausanne, Switzerland (Le Doucen et al., 2009). Further systematic studies are still under way at these laboratories.

As for the traditional labyrinth weirs two different approaches may be used to describe the hydraulic performance of PK weirs.

The first approach uses the standard weir equation and considers all specific PK weir parameter in a modified discharge coefficient:

$$
Q=C_{w} L_{u} \sqrt{2 g} H^{3 / 2}
$$

with $Q$ as discharge, $H$ as total head, $L_{u}$ as developed weir length and $C_{w}$ as global discharge coefficient. In such a way Machiels et al. $(2009 \mathrm{a}, \mathrm{b})$ have presented $C_{w}$ curves as a function of the ratio head over weir height $H / P$ for certain PK weir designs.

The second approach uses the concept of effective crest length (Leite Ribeiro et al., 2007, 2009). A discharge enhancement ratio $r$ between PK weir discharge $Q_{P K W}$ and a sharp crested weir discharge $Q_{w}$ has been defined:

$$
r=\frac{Q_{P K W}}{Q_{w}}=\frac{C_{d} L_{e f f} \sqrt{2 g} H^{3 / 2}}{C_{d} W \sqrt{2 g} H^{3 / 2}}=\frac{L_{e f f}}{W}
$$

Here, $W$ corresponds to the total width of the PK weir. The discharge coefficient $C_{d}$ of the sharp crested standard weir can be assumed as almost constant with $C_{d}=0.42$ (Hager \& Schleiss, 2009).

Based on the different configurations tested in laboratory for Saint-Marc Dam and Gloriettes Dam in France, the following equation could be proposed (Leite Ribeiro et al., 2009)

$$
r=\frac{L_{e f f}}{W}=\frac{1}{\left(\frac{H}{W}+\frac{1}{\sqrt[n]{\frac{L_{u}}{W}-1}}\right)^{n}}
$$

For the two mentioned prototype spillways the exponents n varied between 7.5 and 14.5 depending on the geometrical configuration. 
Further analysis of systematic physical experiments are still needed in order to derive general applicable design rules taking into account all complex geometric features of PK weirs.

The first more classical approach by using a modified discharge coefficient is less physically based but probably easier to assess. The approach using the effective PK weir length describes better the flow physic involved but is probably more difficult to put into operation. A combination of these two approaches may perhaps be promising.

\subsection{Comparison of labyrinth with PK weirs}

Comparing a PK weir with a corresponding rectangular labyrinth weir reveals that the PK weir has a significantly better discharge efficiency if comparing the global discharge coefficient (Anderson \& Tullis, 2011). This is also the case if considering trapezoidal labyrinth weirs for comparison (Blancher et al., 2011). The gain of efficiency with a PK weir can reach $20 \%$.

Finally, the use of PK weirs can also result in considerable construction cost savings compared to traditional labyrinth weirs.

\subsection{Further developments}

The PK weir offers many geometrical options as already presented in 3.1, whose influence has to be tested more systematically in future. Especially the use of side wall angle is promising, which would result in a converging inlet key.

Another not yet considered feature would be to incline slightly the sidewall which enlarges the width of the inlet key. Furthermore a very early springing of the nappe as well as better aeration could be ensured.

\section{CONCLUSIONS}

The hydraulic performance of traditional labyrinth weirs is well known since they have been studied for a long time. Nevertheless, analytical design equations considering all the involved parameters are not yet available. The design has to be based on experimentally derived and generalized performance curves.

In the case of the recent developed PK weirs even such generalized performance curves are not yet available. More systematic laboratory studies on physical models are still needed as well as alternative parametric approaches. The complexity of flow and geometry of PK weir is a fascinating challenge for future experimental and numerical research.

\section{REFERENCES}

Anderson, R. M. and Tullis B. P. 2011. Influence of Piano Key Weir Geometry on Discharge. Proc. International Workshop on Labyrinth and Piano Key Weirs, Liège, Belgium.

Bieri, M., Leite Ribeiro, M., Boillat, J.-L., and Schleiss, A.J. 2009. Réhabilitation de la capacité d'évacuation des crues - intégration de PK-Weir sur des barrages existants. Proc., Colloque CFBRSHF, Dimensionnement et fonctionnement des évacuateurs de crues (CD-ROM), Paris France.

Blancher, B., Montarros, F. and Laugier, F. 2011. Hydraulic comparison between piano-keys weir and labyrinth spillways. Proc. International Workshop on Labyrinth and Piano Key Weirs, Liège, Belgium.

Chi Hien, T., Thanh Son, H. and Ho Ta Khanh, M. 2006. Results of some "Piano Keys" weir hydraulic model tests in Vietnam. Proc., 22nd Congress of Large Dams, Question 87, Response 39. Barcelona, Spain. Volume IV, 581-595.

Cicéro, G.M., Guene, C., Luck, M., Pinchard, T., Lochu, A. , and Brousse, P.H. 2010. Experimental optimization of a piano key weir to increase the spillway capacity of the Malarce dam. 1st IAHR European Congress, Edinbourgh, 4-6 mai 2010.

Crookston, B. M. 2010. Labyrinth weirs. Ph.D. Dissertation. Utah State University, Logan, Utah.

Crookston, B. M. and Tullis B. P. 2011. Hydraulic characteristics of labyrinth weirs. Proc. International Workshop on Labyrinth and Piano Key Weirs, Liege, Belgium.

Darvas, L. A. 1971. Discussion of "Performance and Design of Labyrinth Weirs. Journal of the Hydraulics Division, 97(8), 1246-1251. 
Falvey, H.T. 2003. Hydraulic Design of Labyrinth Weirs. ASCE Press, Reston, VA, United States.

Gentilini, B. 1941. Stramazzi con cresta a pianta obliqua e a zig-zag. Memorie e studi dell'Instituto di Idraulica e Costruzioni Idrauliche del Regio Politecnico di Milano. No. 48. (in Italian).

Hager, W., and Schleiss, A.J. 2009. Traité de Génie Civil, Volume 15 - Constructions Hydrauliques Ecoulements Stationnaires. Presses polytechniques et universitaires romandes, Switzerland.

Hay, N., and Taylor, G. 1970. Performance and design of labyrinth weirs. Journal of the Hydraulics Division, 96(11), 2337-2357.

Houston, K. 1982. Hydraulic model study of ute dam labyrinth spillway Report No. GR-82-7. U.S. Bureau of Reclamation, Denver, Colorado.

ICOLD, 1994. Technical Dictionary on Dams.

Khode, B. V., Tembhurkar, A. R., Porey, D. and Ingle, R. N. 2010. Improving Discharge Capacity over Spillway by Labyrinth Weir. World Applied Sciences Journal 10(6): 709-714.

Lempérière, F., and Ouamane, A. 2003. The Piano Keys weir: a new cost-effective solution for spillways. Hydropower \& Dams, 7 (5): 144-149.

Lempérière, F., Sharma, N., Mourya, R. N., Shukla R. and Gupta, U. P. 2003. Experimental Study on Labyrinth Spillways. Proc. International Conference on Engineering of Dams and Appurtenant Works Including Power Houses \& Transmission Systems (CD-ROM), New Delhi, India.

Leite Ribeiro, M., Boillat, J.-L., Schleiss, A., Laugier, F. and Albalat, C. 2007. Rehabilitation of St-Marc Dam - Experimental Optimization of a Piano Key Weir. Proc., 32nd Congress of IAHR (CD-ROM), Venice, Italy.

Laugier, F. 2007. Design and construction of the first Piano Key Weir (PKW) spillway at the Goulours dam. Hydropower \& Dams, 14 (5): 94-101.

Laugier, F., Lochu, A., Gille, C., Leite Ribeiro, M. and Boillat, J-L. 2009. Design and construction of a labyrinth PKW spillway at St-Marc dam, France. Hydropower \& Dams, 16 (5): 100-107.

Le Doucen, O., Ribeiro, M.L., Boillat, J.-L., Schleiss, A. J. and Laugier, F. 2009. Etude paramétrique de la capacité des PK-Weirs. Modèles physiques hydrauliques - outils indispensables du XXIe siècle, SHF, Lyon.

Leite Ribeiro, M., Bieri, M., Boillat, J-L., Schleiss, A., Delorme, F. and Laugier, F. 2009. Hydraulic capacity improvement of existing spillways - Design of piano key weirs. Proc., 23rd Congress of Large Dams. Question 90, Response 43 (CD-ROM), Brasilia, Brazil.

Lopez, R., Matos, J. and Melo, J. 2008. Characteristic depths and energy dissipation downstream of a labyrinth weir. 2nd Int. Junior Researcher and Engineer Workshop on Hydraulic Structures, Pisa, Italia.

Lux, F. and Hinchliff, D. 1985. Design and construction of labyrinth spillways. 15th Congress ICOLD, Vol. IV, Q59-R15, Lausanne, Switzerland, 249-274.

Machiels, O., Erpicum, S., Archambeau, P., Dewals, B.J. and Pirotton, M. 2009a. Analyse expérimentale $\mathrm{du}$ fonctionnement hydraulique des déversoirs en touches de piano. Colloque CFBR-SHF: "Dimensionnement et fonctionnement des évacuateurs de crues", Paris, France.

Machiels, O., Erpicum, S., Archambeau, P., Dewals, B. J. and Pirotton, M. 2009b. Large scale experimental study of piano key weirs. Proc., 33rd Congress of IAHR (CD-ROM), Vancouver, Canada.

Magalhães Pinto, A. 1985. Labyrinth-weir spillways. $15^{\text {th }}$ Congress ICOLD, Vol. IV, Q59-R24, Lausanne, Switzerland, 395-407.

Ouamane, A. and Lempérière, F. 2006. Design of a new economic shape of weir. Proc., International Symposium on Dams in the Societies of the 21st Century, Barcelona, Spain. 463-470.

Sharma, N., and Singhal, G. 2008. A dam safety solution by Piano Key Weir for enhanced spillway capacity. Proc., International Conference on Hydrovision, Sacramento, United States.

Taylor, G. 1968. The performance of labyrinths weirs. PhD thesis. University of Nottingham, Nottingham, United Kingdom.

Tullis, J. P., Amanian, N., and Waldron, D. 1995. Design of Labyrinth Spillways. Journal of Hydraulic Engineering, 121(3), 247-255.

Tullis, B.P., Willmore, C.M. and Wolfhope, J.S. 2005. Improving performance of low head labyrinth weir. J. Hydr. Eng. ASCE, 173: 418-426.

Tullis, B., Young, J., and Chandler, M. 2007. Head-discharge relationships for submerged labyrinth weirs. American Society of Civil Engineering, Journal of Hydraulic Engineering 133(3), 248-254.

Vermeulen, J., Laugier, F., Faramond, L. and Gille, C. 2011. Lessons learnt from design and construction of EDF first Piano Key Weirs. Proc. International Workshop on Labyrinth and Piano Key Weirs, Liège, Belgium.

Willmore, C. 2004. Hydraulic characteristics of labyrinth weirs. M.S. Report, Utah State University, Logan, Utah.

Yildiz, D. and Üzücek, E. 1996. Modelling the performance of labyrinth spillways. Hydropower \& Dams, 3 (3): 71-76. 